\title{
Rotordynamic Coefficients of Long Staggered Labyrinth Gas Seals
}

\author{
K. KWANKA and W. ORTINGER \\ Lehrstuhl Thermische Kraftanlagen, Technische Universtität München
}

\begin{abstract}
Experimental and theoretical investigations concerning a long staggered labyrinth gas seal are presented. Accurate static measurements help to assess the influence of the entry swirl, the rotational speed and the pressure difference on the conservative and the nonconservative force. For a better understanding of the phenomena the forces in each cavity are investigated. A coupling between the circumferencial flow and the axial flow in the cavity is revealed. The theoretical results are obtained by a one-volume bulk-flow theory which is essentially based on the momentum equation in circumferencial direction and therefore neglects some effects caused by the axial flow. The experimental results are compared to calculated results.
\end{abstract}

\section{INTRODUCTION}

$\mathbf{H}_{0}$ igh power density turbomachines often work at parameter values very close to the stability limit. In the unstable region the rotor performs self-excited bending vibrations with a frequency which is normally close to the first critical speed. Self-excited vibrations are essentially caused by fluid mechanisms in journal bearings and labyrinth seals transfering energy into the rotor vibration. The unacceptable high amplitudes of the self-excited vibrations can severely affect the safe and reliable operation of the turbomachine. An exact prediction of the stability limit requires a good modelling of the exciting mechanisms and, as a consequence, a reliable evidence about the forces acting on the rotor. Based on the assumption of small deflections out of the centered position, a linearized formulation of the labyrinth seal forces is usually used.

$\vec{F}=-\left(\begin{array}{cc}K & k \\ -k & K\end{array}\right)\left(\begin{array}{c}x \\ y\end{array}\right)-\left(\begin{array}{cc}C & c \\ -c & C\end{array}\right)\left(\begin{array}{c}\dot{x} \\ \dot{y}\end{array}\right)-\left(\begin{array}{cc}E & e \\ -e & E\end{array}\right)\left(\begin{array}{c}\ddot{x} \\ \ddot{y}\end{array}\right)$

The force acting on the rotor can be splitted in a conservative restoring and a nonconservative cross force. In most cases, the main source of instability is the cross-coupled stiffness. The experimental identification of the direct and the cross-coupled stiffness is realized by so called static measurements (Hauck [1982], Thieleke and Stetter [1990], Benckert and Wachter [1980] Leong and Braun [1984]). Despite the fact that the restoring force is conservative it has however an influence on the critical speeds and the deflection of the vibrational modes, and as a consequence on the stability. This can be relevant especially when the rotor is slim and/or labyrinth seals are placed in a central position between the bearings.

Dynamic measurements are effected to identify the dynamic damping and inertia coefficients of the labyrinth seal (Childs et al. [1986], Nordmann and Massmann [1984]). These coefficients are highly important especially when the fluid is dense and/or when the whirling frequency is high.

The various theoretical approaches can be validated by means of these experimental results. In addition, the involved models can be improved, if necessary, and the used simplifications reviewed. The computational effort is low when a lumped parameter model-either a one-, two-, or three-volume model is used (Baumgartner [1987], Childs and Scharrer [1986], Nordmann and Weiser[1990]). When computational fluid dynamic methods are applied, the geometry of the investigated cavity is discretized by a grid and the local variables (velocity, 
pressure) are calculated (Nordmann and Weiser [1988]). This case requires a higher computational time and, therefore renders, parametric studies more difficult.

Extensive experimental investigations on multistage gas labyrinth seals with varios cavity geometry were carried out by Benckert and Wachter [1980]. Among others, a staggered 10-cavity labyrinth geometry with grooves and tooth on stator and fins on rotor was investigated. For long seals the rotation turned out to have a significant influence. Benckert and Wachter [1980] stated that the cross-coupled stiffness arised primarily because of the circumferential velocity which depends not only on the rotating speed but also on the ratio of rotating and nonrotating cavity walls. No information was given about the cavity to cavity distribution of the forces. The maximum adjusted pressure ratio was 0.35. Leong and Brown [1984] tested a number of labyrinth geometries with strips attached to the stator. The maximum pressure ratio investigated was 0.28 . They found considerable decenterizing forces and negative stiffness coefficients due to rotation without entry swirl. Thieleke and Stetter [1990] presented additional test results for staggered labyrinth seals with maximum eight cavities in a teeth on stator configuration using the apparatus of Benckert and Wachter [1980].

In this paper experimental investigations performed on a 14-cavity staggered teeth on stator labyrinth gas seal are presented. The stiffness coefficients are measured with the static identification method. First results showing the overall tendencies are presented by Kwanka et al. [1993]. The flow-induced reaction forces yielded decenterizing restoring forces exceeding the magnitude of the cross forces for all parameters. The influence of the entry swirl on the cross force was considerably higher than that of the rotational speed. It was the change of the circumferential velocity which was decisive for the magnitude of the cross force, not the absolute value. The measured force-deflection relationships were reasonably linear out to an eccentricity ratio of 0.8 . Therefore, the linear model used in Eq. (1) is justified.

Despite the numerous efforts in the past some discrepancies between experimentally measured and theoretically predicted labyrinth forces still cannot be explained. It is necessary to examine the cavity to cavity distribution of the forces in order to obtain a better insight into the prevailing physical phenomena. The static identification method used guarantees a high accuracy of the measured stiffness coefficients, which in most cases are of outstanding importance for the dynamic behavior of the rotor. The comparison with calculated results obtained by an one-volume bulk-flow model would then show the suitability of the theoretical approach.

\section{EXPERIMENTAL INVESTIGATIONS}

The test rig was designed and built to measure the radial forces which are induced by the flow through labyrinth seals on the eccentric rotor. An overall layout of the test rig is shown in fig. 1a. Two identically grooved labyrinth seals with fourteen cavities each are located symmetrically to the inflow region. Cooled, dried and metered air from a compressor enters the test rig through an inflow device (fig. 1b). By combination of radial and circumferential flow components the inlet swirl can be varied.

One of the seals is used to measure the pressure distribution in circumferential direction and, as a consequence, the acting force in each cavity as well as on the rotor as a whole. Ten pressure sensing holes are located on the outer circumference of each cavity. The circumferential pressure distributions were integrated to obtain forces which were splitted into components parallel and perpendicular to the displacement. The 160 pressure lines are connected to a multifunction pressure measurement rig. The inlet swirl and the flow field in the cavities

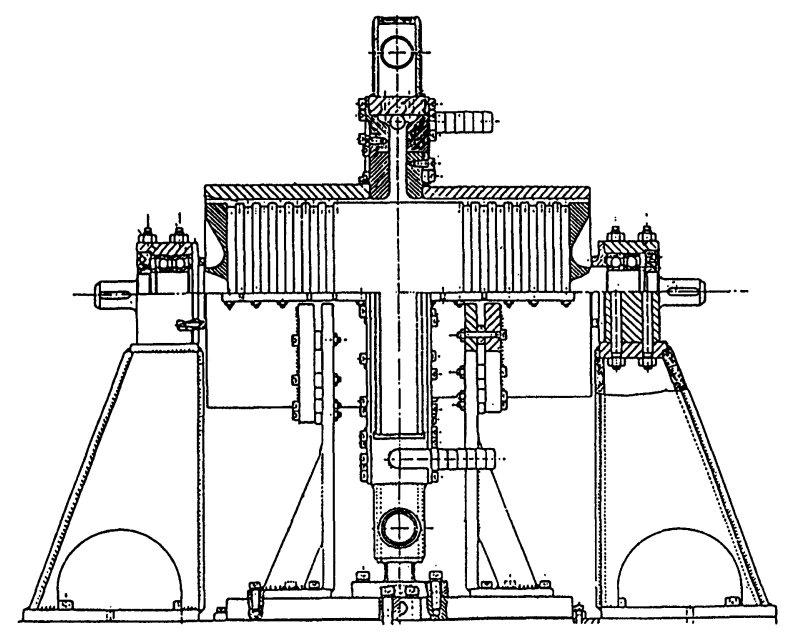

FIGURE 1a Schematic of the test rig.

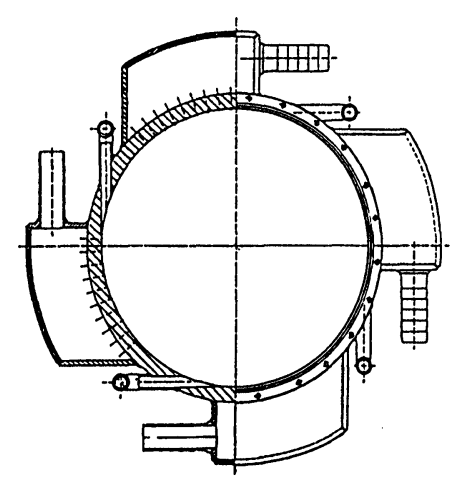

FIGURE 1b Inflow configuration of the test rig. 


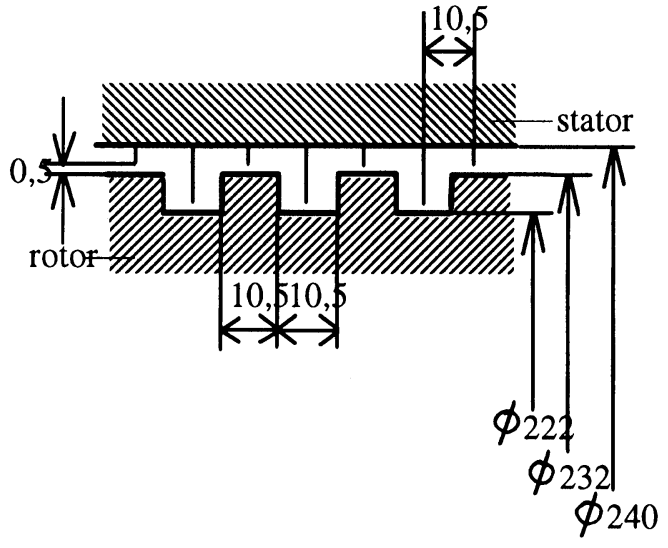

FIGURE 2 Geometrical data of the labyrinth test rig (dimensions in $\mathrm{mm})$.

can be measured through outlets in the casing of the opposite seal by using a probe.

In fig. 2 the geometrical data of the staggered labyrinth are indicated. Some additional test rig dimensions and experimental conditions are listed in table 1 . The static eccentricity can be adjusted in horizontal direction by moving the casing relative to the rotor forwards as well as backwards. When the test rig is supplied only via the tangential feeders, the maximum preswirl velocity direct upstream of the seal is about $22 \mathrm{~m} / \mathrm{s}$. This velocity is nearly constant for all pressure ratios investigated in this paper due to the simultaneous increase of the mass flow and the density. Choked flow prevails in the gap between the exit seal tip and the rotor when the highest pressure difference of $\Delta \mathrm{p}=460 \mathrm{kPa}$ is adjusted. Further details about the test rig and the experimental procedure are given by Steckel [1993]. In a staggered labyrinth the geometrical shape of the cavities changes alternately. The change from the grooved to the toothed rotor section has a greater impact on the axial flow than the change from the toothed to the grooved section. This was confirmed by numerical investigations which show that the axial flow and the strength of the cavity whirl

TABLE 1

Test rig dimensions and experimental conditions

\begin{tabular}{lll}
\hline Diameter (stator) & $\mathrm{D}[\mathrm{mm}]$ & 240 \\
Length (seal) & $\mathrm{L}[\mathrm{mm}]$ & 150 \\
Clearance $(\mathrm{e}=0)$ & $\mathrm{d}[\mathrm{mm}]$ & 0,5 \\
Eccentricity & $\mathrm{e}[\mathrm{mm}]$ & $\max .0,4$ \\
Pressure difference & $\Delta \mathrm{p}[\mathrm{kPa}]$ & $\max .460$ \\
Rotating speed & $\mathrm{n}[\mathrm{rpm}]$ & ${ }^{ \pm} 8000$ \\
\hline
\end{tabular}

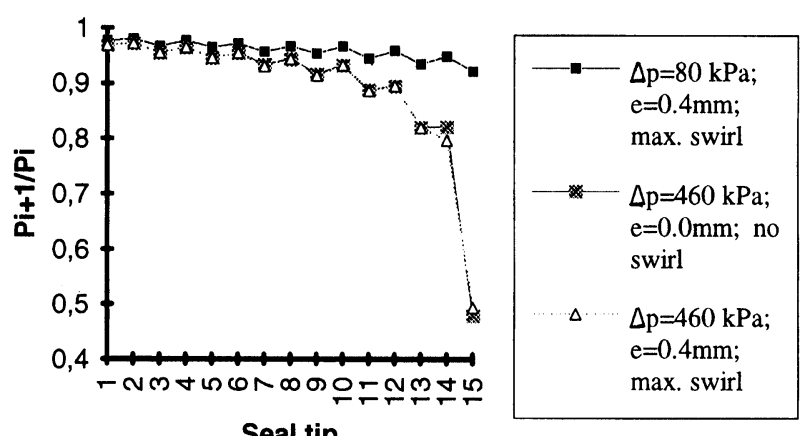

Seal tip

FIGURE 3 Pressure drop in the labyrinth seal.

induced by this flow depends on the geometry (Baumgartner [1987], Nordmann and Weiser [1988]. As a consequence, the pressure is declining in big and small steps alternately (fig. 3). Together with the geometrydependent flow area this causes alternately high and low flow coefficients (Kwanka et al. [1993]).

In the center position of the rotor the circumferencial pressure distribution is nearly constant and therefore no forces act on the rotor as a whole. Nevertheless, the small forces for each cavity in normal and cross direction in center position can be used to correct measurements performed with the eccentric rotor (fig. 4). These forces are mostly insensitive to the rotational speed and the entry swirl whereas the pressure ratio has a great impact. Even if the forces in centered position are small, they still represent the main cause for divergencies and are due to random variations in the actual fin clearance. The use of the forces in centered position for correctional purposes is not necessary when the data points at positive and negative eccentricity are averaged. This procedure is applied to all following measurements with eccentric rotor.

Although forces induced in gas seals are at least one order of magnitude lower than in liquid seals, the

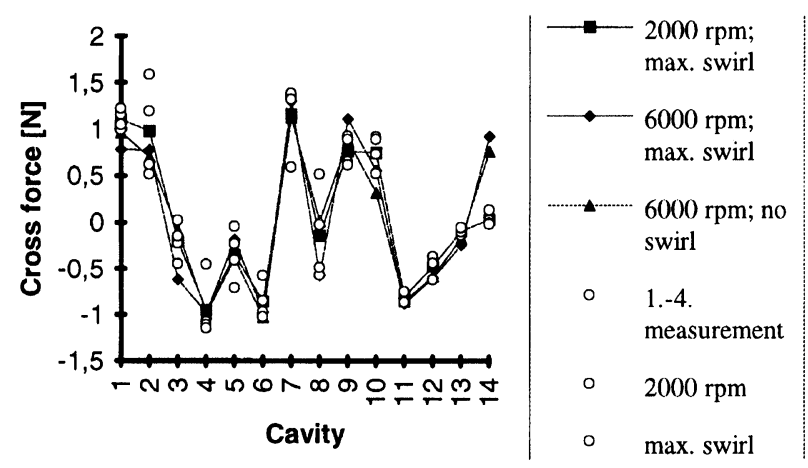

FIGURE 4 Cross forces in centered position of the rotor $(\mathrm{e}=0.0 \mathrm{~mm})$ 


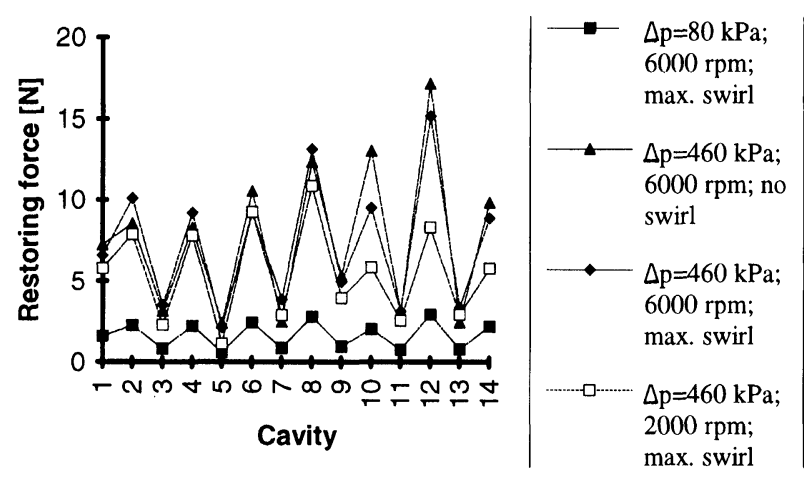

FIGURE 5 Restoring force depending on several parameters $(e=0.4$ $\mathrm{mm})$.

measurements display a good reproducibility. In addition to the averaged values four particular mesurements are shown in fig. 4. The mean uncertainty of the averaged force per cavity is about $0.33 \mathrm{~N}$.

The restoring force which was measured in eccentric position shows a behavior, similar to the correction forces (fig. 5). Again the preswirl and the rotation have only little influence on the course and the magnitude of the forces. The pressure difference on the other hand has a considerable influence and finally indicates that the restoring force is generated by the axial flow (fig. 6). In the cavities where the grooved section is followed by a tooth the restoring forces are considerably higher than the forces in the other cavities.

The restoring force arises due to pressure differences which occur on the perimeter and which basically should influence also the circumferencial flow. The same alternating behavior of the restoring force was found by Thieleke and Stetter [1990] in that case; however, the total force was about zero.

In a next step the cross force will be examined. When small pressure differences are adjusted, the density of the
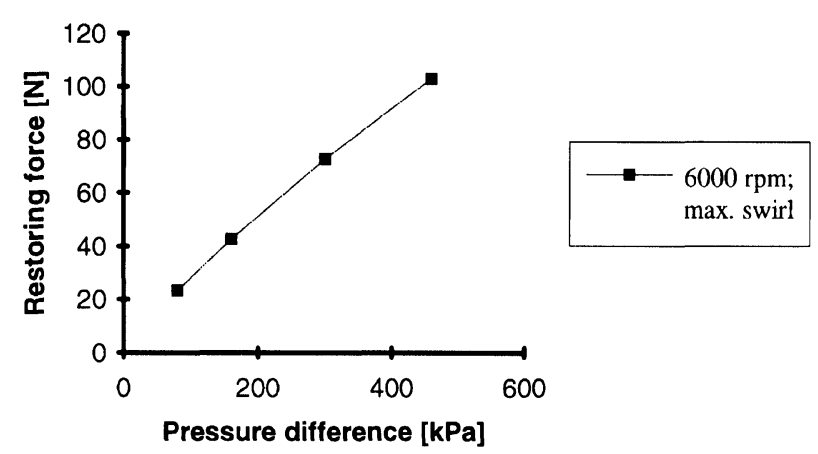

FIGURE 6 Restoring force versus the pressure difference on the seal $(\mathrm{e}=0.4 \mathrm{~mm})$. air at the entrance section of the seal is small, too. Therefore, for a given entry swirl, which is a nearly constant value for all pressure differences $\left(c_{u} \approx 22 \mathrm{~m} / \mathrm{s}\right)$, the momentum in circumferencial direction is low for small densities. In addition to the swirl, the axial flow seems to have an influence on the generation of the cross force (fig. 7a). The peaks of the cross force correspond to the peaks of the restoring force in the front part of the seal. This phenomenon shows a good reproducibility for all rotating speeds.

Nevertheless, the cross force declines smoothly in the first part of the seal when the circumferencial flow in the cavity is dominated by swirl due to a high pressure level (fig. 7b). In the rear part of the seal the influence of swirl decreases and again the cross force seems to be controlled by the axial flow.

In case of no shaft rotation, mainly the part of the cross force resulting from the entry swirl appears (fig. 8). The above-mentioned change in the behavior of the cross force comes about gradually and depends clearly on the pressure level.

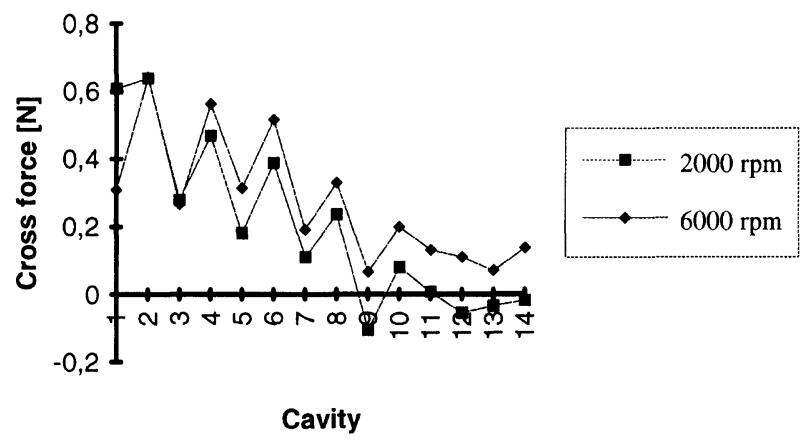

FIGURE 7a Course of cross force for a small pressure drop $(\Delta \mathrm{p}=80$ $\mathrm{kPa} ; \mathrm{e}=0.4 \mathrm{~mm}$ ).

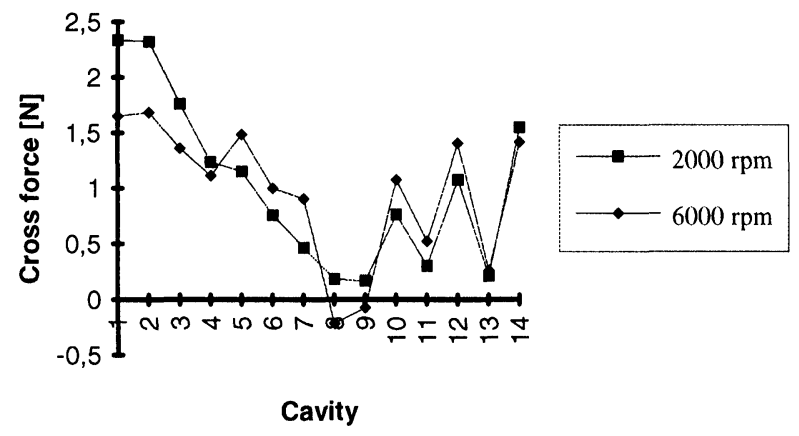

FIGURE $7 \mathrm{~b}$ Course of cross force for a high pressure drop $(\Delta \mathrm{p}=460$ $\mathrm{kPa} ; \mathrm{e}=0.4 \mathrm{~mm}$ ). 
$\Delta p=460 \mathrm{kPa} ; \mathrm{e}=0.4 \mathrm{~mm}$; max. swir

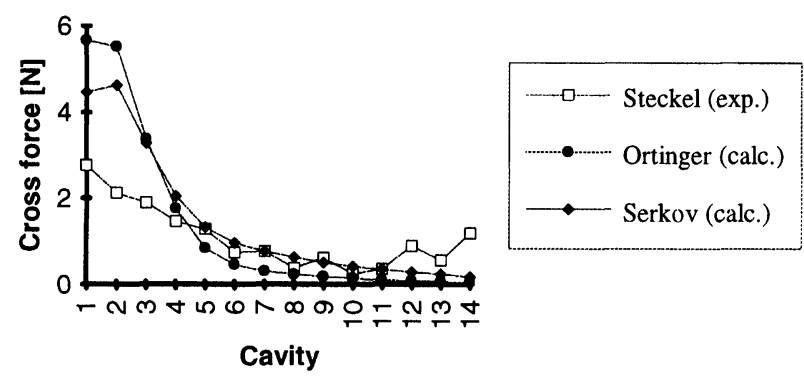

FIGURE 8 Comparison of calculated and measured cross forces for the nonrotating shaft and maximum entry swirl.

\section{THEORETICAL TREATMENT AND COMPARISON TO EXPERIMENT}

With the help of a bulk-flow theory the circumferential pressure distribution due to the eccentric position of the rotor relative to the casing is obtained. Details of the calculation method can be seen in Baumgartner [1987].

The principal equations are the same as used by other authors (Childs and Scharrer [1986], Thieleke and Stetter [1990]):

$$
\begin{gathered}
\dot{\mathrm{m}}_{\mathrm{i}}=\mu_{\mathrm{i}} \delta_{\mathrm{i}} \sqrt{\mathrm{p}_{\mathrm{i}-1}^{2}-\mathrm{p}_{\mathrm{i}}^{2}} \\
\frac{\partial}{\partial \mathrm{t}}\left(\rho_{\mathrm{i} \mathrm{i}}^{\mathrm{f}}\right)+\frac{\partial}{\mathrm{R}_{\mathrm{R}} \partial \sigma}\left(\rho_{\mathrm{i}} \mathrm{c}_{\mathrm{ui}} \mathrm{f}_{\mathrm{i}}\right)+\dot{\mathrm{m}}_{\mathrm{i}+1}-\dot{\mathrm{m}}_{\mathrm{i}}=0 \\
\frac{\partial \mathrm{c}_{\mathrm{ui}}}{\partial \mathrm{t}}+\mathrm{c}_{\mathrm{ui}} \frac{\partial \mathrm{c}_{\mathrm{ui}}}{\mathrm{R}_{\mathrm{R}} \partial \varphi}+\dot{\mathrm{m}}_{\mathrm{i}} \frac{\mathrm{c}_{\mathrm{ui}}-\mathrm{c}_{\mathrm{ui}-\mathrm{i}}}{\rho_{\mathrm{i}} \mathrm{f}_{\mathrm{i}}}+ \\
+\mathrm{k}_{\mathrm{Si}} \mathrm{c}_{\mathrm{ui}}^{2}-\mathrm{k}_{\mathrm{Ri}}\left(\mathrm{R}_{\mathrm{R}} \omega-\mathrm{c}_{\mathrm{ui}}\right)^{2}=-\frac{\partial \mathrm{p}_{\mathrm{i}}}{\rho_{\mathrm{i}} \mathrm{R}_{\mathrm{R}} \partial \varphi} \\
\mathrm{K}_{\mathrm{Si}}=\lambda_{\mathrm{Si}} \frac{\mathrm{U}_{\mathrm{Si}}}{2 \mathrm{f}_{\mathrm{i}}} \operatorname{sgn}\left(\mathrm{c}_{\mathrm{ui}}\right) \\
\mathrm{K}_{\mathrm{Ri}}=\lambda_{\mathrm{Ri}} \frac{\mathrm{U}_{\mathrm{Si}}}{2 \mathrm{f}_{\mathrm{i}}} \operatorname{sgn}\left(\mathrm{R}_{\mathrm{R}} \omega-\mathrm{c}_{\mathrm{ui}}\right)
\end{gathered}
$$

This is the well-known set of partial differential equations. In order to find an analytical solution, the differential equation system is linearized by dividing the main variables into an average value (for the centric position) and an additional value (for the eccentric position). This perturbation method is applied for eight terms.

$$
\begin{array}{ll}
\delta=\delta_{*}(1+\psi) & \mathrm{f}=\mathrm{f}_{*}(1+\Xi) \\
\dot{\mathrm{m}}=\dot{\mathrm{m}}_{*}(1+\zeta) & \mathrm{p}=\mathrm{p}_{*}(1+\xi) \\
\mathrm{c}_{\mathrm{u}}=\mathrm{c}_{\mathrm{u}^{*}}(1+\eta) & \mu=\mu_{*}(1+\tilde{\mathrm{n}}) \\
\lambda_{\mathrm{R}}=\lambda_{\mathrm{R} *}\left(1+\Lambda_{\mathrm{R}}\right) & \lambda_{\mathrm{s}}=\lambda_{\mathrm{s}^{*}}\left(1+\Lambda_{\mathrm{s}}\right)
\end{array}
$$

For the calculation of the mass-flow coefficient $\mu$ the method of Neumann is used in the program. The calculated mass-flow coefficient is adapted to the geometry investigated here, but not changed from cavity to cavity as found out by the experiments. Eqs. (6) are inserted in eqs. (2)-(5), and an exponential formulation for the perturbation term leads to the cross force acting on the rotor.

$$
F=-R_{R} l p_{*} \int_{0}^{2 \pi} \zeta \sin \varphi d \varphi
$$

With the aid of this perturbation method it is possible to calculate the force in a first step, and, in a second step, to obtain the dynamic coefficients of the seal. The calculation only partly indicates the normal forces. The part results from the rotational flow in the cavity. In case of eccentricity without rotation, only the axial flow persists and no forces are predicted. Therefore, the calculated restoring forces cannot be compared to experimental data.

In the perturbation analysis the friction factor of the stator $\lambda_{S}$ and the friction factor of the rotor $\lambda_{R}$ are calculated by solving the Navier-Stokes equations in connection with a $k-\epsilon$ turbulence model for the labyrinth geometry used. By means of a boundary-layer theory, the wall shear stresses of the flow relative to the stator/rotor are calculated. This leads to the friction factor. For detailed information see Ortinger [1992].

Other methods to obtain the friction factor are given in the program, too. For example, Serkov's calculation of the friction factor is based on Dorfman's formulation for the long annular gap. By experimental investigations Serkov [1986] found out that the behavior of the friction factor in labyrinth seals is similar to those in annular gaps. The friction factor of the annular gap must be multiplied with a geometry-dependent amplification factor $\chi$. The range of this factor varies from 3.5 to 5.9. For the geometry used here a factor $\chi=4.9$ was found out. Ortinger [1992] published a survey of friction factors obtained by various methods and authors.

The following calculations are performed with calculated friction factors which are obtained by the methods mentioned above. The applicability of the bulk-flow 
$\Delta p=460 \mathrm{kPa} ; \mathrm{e}=0.4 \mathrm{~mm} ; 6000 \mathrm{rpm} ; \max$. swirl

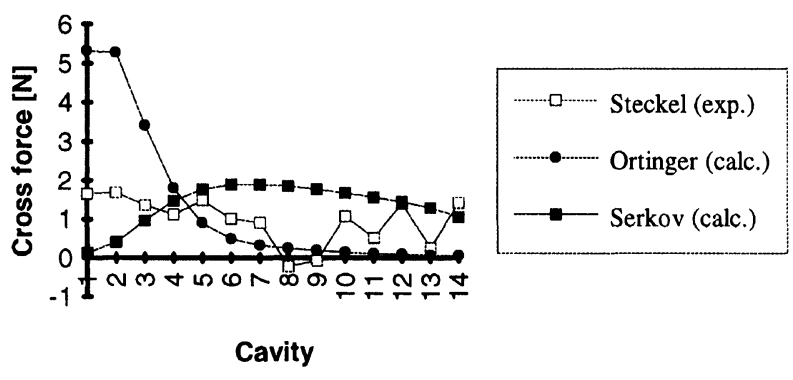

FIGURE 9 Comparison of calculation and experiment in case of rotating shaft.

model to the static identification method is documented (Childs and Scharrer [1986], Thieleke and Stetter [1990]). First, the comparison of calculation and experiment is presented for the nonrotating shaft and maximum preswirl (fig. 8). The coincidence of the calculated course of the cross force on the one hand and the measured results on the other hand is satisfactory.

Even though the total force for the whole labyrinth does not differ much, the discrepancies in the distribution are evident (fig. 9). The experimental data in the first cavities decrease due to rotation, as prior measurements show (Kwanka et al. [1993]). The calculated results obtained by using the friction factors of Ortinger are nearly the same as in the nonrotating case, whereas when the calculations are performed with the friction factors of Serkov the influence of rotation is overestimated. These results show that the calculation method is highly sensitive to friction factors.

Both calculations do not predict the oscillation of the cross force in the rear part of seal. The one volume bulk-flow theory involves some simplifications which do not account for the real flow field in the cavity. Instead of the axial momenum equation a leakage equation is used.

e=0.4 mm; 6000 rpm; max. swirl

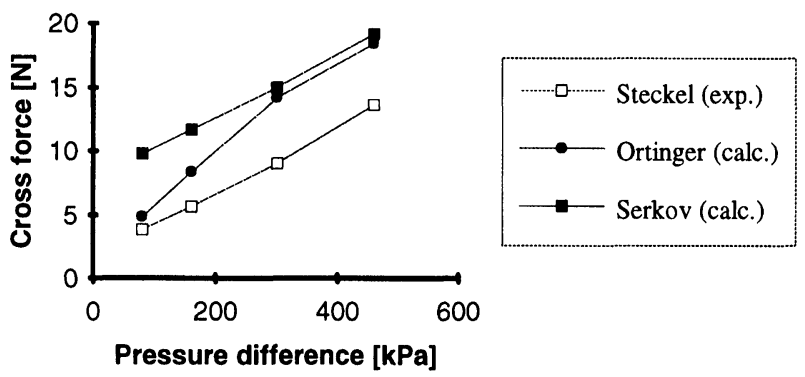

FIGURE 10 Calculation and experiment depending on the pressure difference.
Only the circumferential velocity is involved in calculating wall shear stress which is assumed to be constant at the stationary and rotating boundaries of the cavity respectively.

As shown in this paper, the pressure difference has an impact on the radial forces acting on the rotor. The comparison of calculated and measured total cross forces shows that the tendency depending on the pressure difference is predicted well (fig. 10). (The total cross force divided by eccentricity actually coresponds to the cross coupled stiffness of the seal.) Further improvements in the absolute value will probably require a more accurate modellation of the flow among others.

\section{CONCLUSIONS}

A fourteen cavity staggered labyrinth gas seal is investigated in order to obtain a better insight into the influence of preswirl, rotation of shaft and axial flow on the radial forces which act on the rotor. The cavity by cavity distribution of the forces is obtained from the circumferential pressure distribution when the rotor is moved out of his central position.

The pressure declines in big and small steps due to alternating flow coefficients. The normal force which acts in decenterizing direction changes depending on the geometrical shape of the cavity. The normal force is mainly influenced by the pressure difference adjusted on the labyrinth seal and is essentially generated by the axial flow. The normal forces indicate that a circumferential pressure differences exist which under certain circumstances can even influence the cross forces. In this case, the course of the cross force shows the same alternating behavior as the normal force.

The prediction of the cross force distribution by calculation is good when the rotor does not rotate. The discrepances in the course of the force between calculations with different friction factors are considerable when the shaft rotates. The one-volume bulk flow theory does not predict the part of normal force induced by the axial flow and therefore cannot consider that influence on the cross force.

Nomenclature
$C, E, K, c, e, k$
$F$
$H$
$U$
$c_{u}, c_{a x}$
$e$
$f, l$

Damping, inertia, stiffness coefficients Force Labyrinth height Part of cavity perimeter Circumferential velocity, axial velocity Eccentricity Cross-sectional area, length of cavity 


$\begin{array}{ll}\dot{m} & \text { Mass flow related to circumference } \\ n & \text { Rotating speed } \\ p & \text { Pressure } \\ R_{R} & \text { Radius of rotor } \\ \delta & \text { Radial clearance } \\ \varphi & \text { Peripheral angle } \\ \kappa & \text { Isentropic coefficient } \\ \lambda & \text { Friction factor } \\ \mu & \text { Flow coefficient, dynamic viscosity } \\ \Psi, \xi, \Lambda, \Xi, \eta, \zeta, \tilde{n} & \text { Perturbation terms } \\ \omega & \text { Angular velocity } \\ \rho & \text { Density } \\ & \\ \text { Indices } & \\ * & \end{array}$

\section{References}

Baumgartner M., 1987. Evaluation of Exciting Forces in Turbomachinery Induced by Flow in Labyrinth Seals, $11^{\text {th }}$ ASME Conf. on Mech. Vib. and Noise, Boston, vol. 2, pp. 337-346.

Baumgartner M., 1989. Berechnung von Querkräften an Turborotoren verursacht durch die Strömung in Labyrinthdichtungen, Dissertation TU München.

Benckert, H., Wachter, J. 1980. Flow Induced Spring Coefficients of Labyrinth Seals for Application in Rotordynamics, NASA Conference Publication 2133, pp. 189-212.

Childs D., Nelson C., Nicks C., Scharrer J., Elrod D., Hale K., 1986. Theory versus Experiment for the Rotordynamic Coefficients of Annular Gas Seals, Part 1-Test Facility and Apparatus, ASME J Tribology, vol. 108, pp. 426-432.

Childs D., Scharrer J., 1986. An Iwatsubo-based Solution for Labyrinth
Seals. Comparison to Experimental Results, J. Eng. for Gas Turbines and Power, vol. 108, pp. 599-604.

Hauck L., 1982. Measurement and Evaluation of Swirl-Tip Flow in Labyrinth Seals of Conventional Turbine Stages, NASA Conference Publication 2250, pp. 242-259.

Kwanka K., Ortinger W., Steckel J., 1993. Calculation of the Influence of Flow Parameters on Rotordynamic Coefficients in Labyrinth Seals, NASA Conference Publication 3239.

Leie B., Thomas H.-J., 1980. Self-excited Rotor Whirl Due to Tip-Seal Leakage Forces, NASA Conference Publication 2133, pp. 303-316.

Leong, Y. M. M. S., Brown, R. D., 1984. Experimental Investigations of Lateral Forces Induced by Flow Through Model Labyrinth Glands. NASA Conference Publication 2338, pp. 187-196.

Nordmann R., Massmann H., 1984. Identification of Stiffness, Damping and Mass Coefficients for Annular Seals, IMechE, Paper C 280/84, pp. 159-166.

Nordmann, R., Weiser, P. 1990. Evaluation of Rotordynamic Coefficients of Look-Through Labyrinth by Means of a Three Volume Bulk Flow Model, NASA Conference Publication 3122, pp. 147-163. Nordmann, R., Weiser P., 1988. Rotordynamic Coefficients for Labyrinth Seals Calculated by Means of a Finite Difference Technique, NASA Conference Publication 3026, pp. 161-175.

Ortinger W., 1992. The Calculation of Friction Factors in a Labyrinth Seal by Means of Turbulent Flow Computation, Preprints ISRO MAC-4, Honolulu, vol. A, pp. 340-349.

Steckel J., 1993. Experimentelle Untersuchungen zum Durchflu $\beta$ - und Radialkraftverhalten einer Labyrinthdichtung, Dissertation $T U$ München.

Serkov, S. A., 1986. Die Bestimmung von aerodynamischen Kräften in Turbinendichtungen zur Erhöhung der Grenzstabilit t, Wärme 92, $H$. 4-5, pp. 79-83.

Thieleke G., Stetter H., 1990. Experimental Investigations of Exciting Forces Caused by Flow in Labyrinth Seals, NASA Conference Publication 3122, pp. 109-134. 

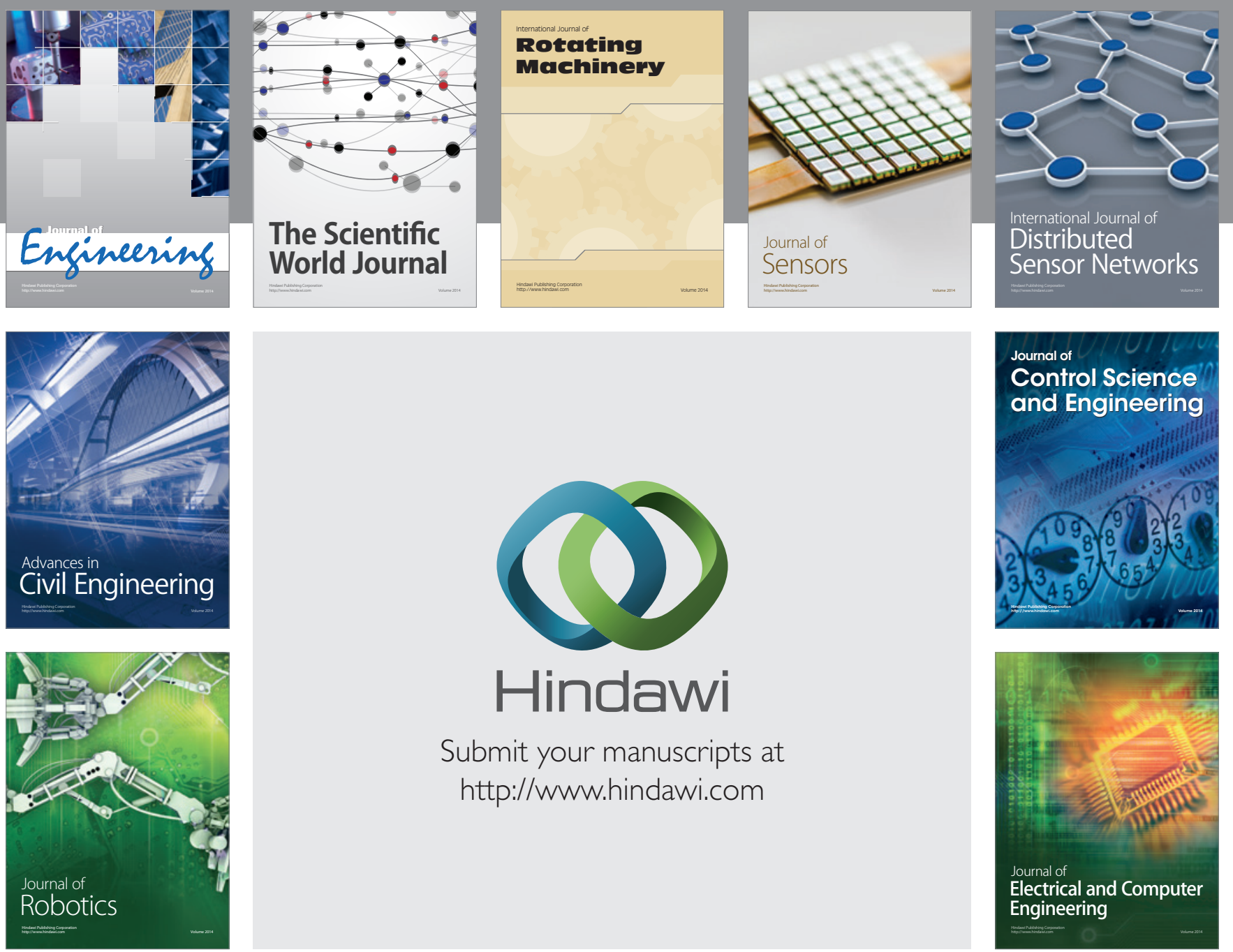

Submit your manuscripts at

http://www.hindawi.com
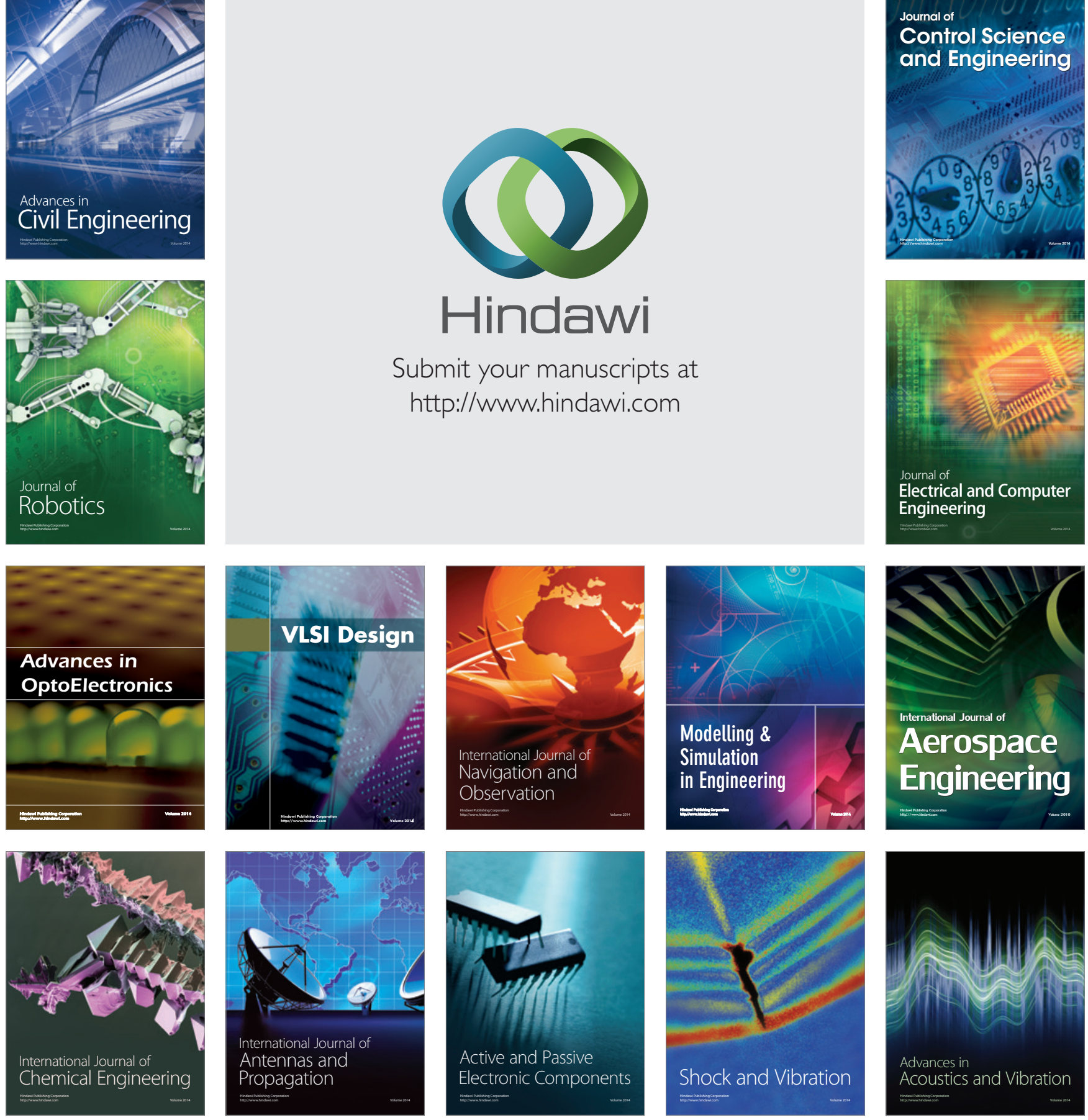